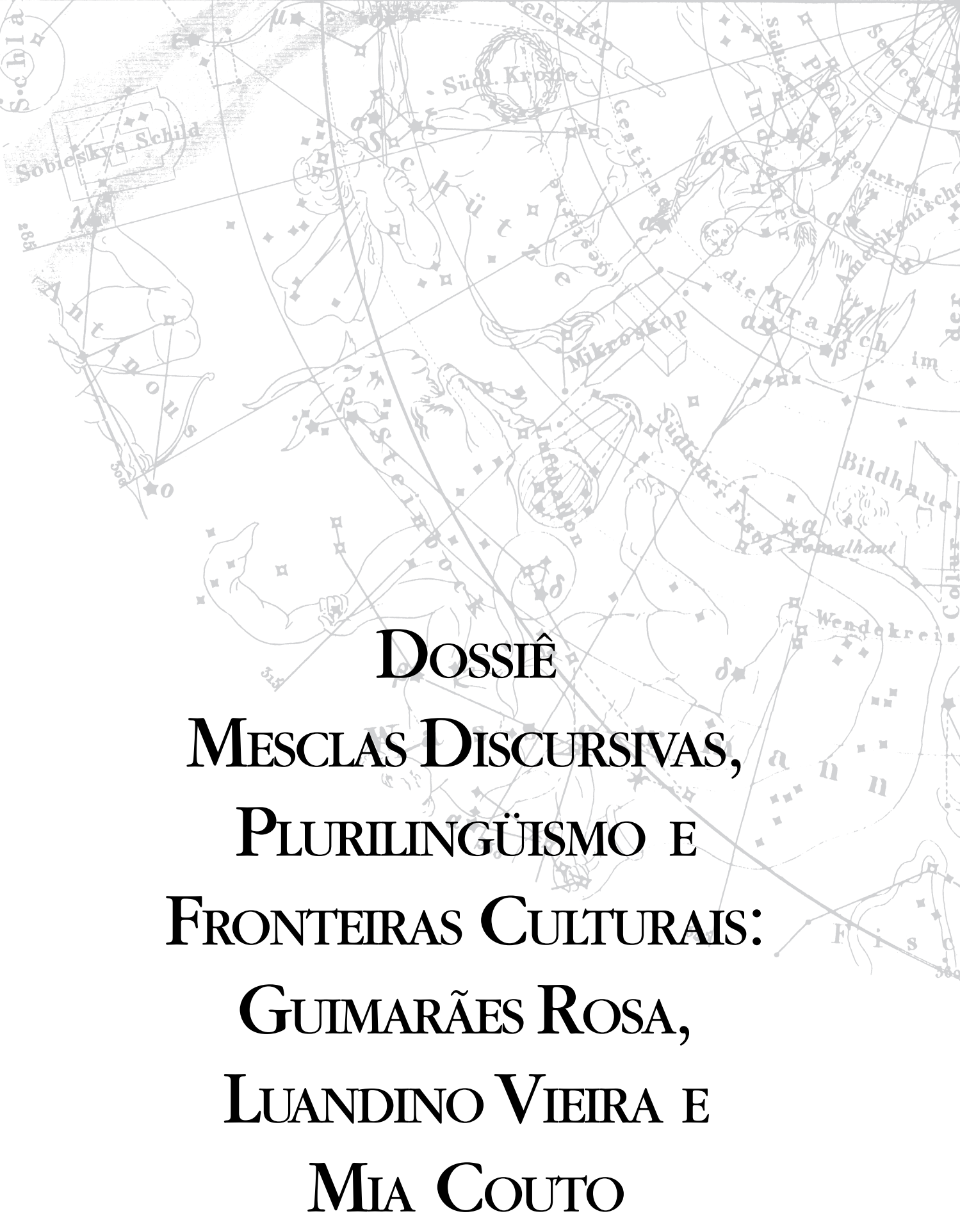





\title{
A dança do Sol e da Lua na obra de Guimarães Rosa ${ }^{1}$
}

\author{
LUIZ RONCARI \\ Universidade de São Paulo
}

RESUMO: ESTE TRABALHO MOSTRA COMO O MOTIVO DA DANCCA DO SOL E DA LUA ATRAVESSA OS TRÊS PRIMEIROS LIVROS DE GUIMARÃES ROSA E SE RELACIONA COM A TRIAADE AMOROSA AMOR FERINUS - AMOR HUMANUS - AMOR DIVINUS PRESENTE NA OBRA DO AUTOR.

ABSTRACT: THIS ARTICLE ANALYZES THE THEME OF THE DANCE BETWEEN SUN AND MOON WITHIN THE THREE FIRST BOOKS PUBLISHED BY GUIMARÃES ROSA, SHOWING ITS RELATIONS WITH THE TRIAD OF AMOR FERINUS - AMOR HUMANUS - AMOR DIVINUS PRESENT IN THE AUTHOR'S LITERARY WORKS.

PALAVRAS-CHAVE: GUIMARÃES ROSA - LITERATURA BRASILEIRA - SIMBOLISMO SOL/LUA KEY-WORDS: GUIMARÃES ROSA - BRAZILIAN LITERATURE - SYMBOLISM OF THE SUN/MOON

\footnotetext{
${ }^{1}$ Este trabalho foi apresentado pela primeira vez na X Feira Pan-Amazônica do Livro, em 20 de setembro de 2006, na cidade de Belém do Pará.
} 
motiv da dança do Sol e da Lua, entre outros, atravessa e costura os três prime os livros de Guimarães Rosa: Sagarana, Corpo de baile e Grande sertão: vered. O que farei nesta pequena exposição será apenas apontar como ele se combina com a representação da tríade amorosa do autor, a do amor ferinus, amor bumanus e amor divinus, segundo a classificação de Marsílio Ficino, que corresponde, ao mesmo tempo, à tripartição da vida amorosa na sociedade patriarcal brasileira: a mulher oficial para a prole, a parceira sexual buscada na senzala e nos seus desdobramentos, e o amigo íntimo escolhido para a interlocução e confissão.

Porém, a importância e o significado do tema precisam ser ainda mais bem investigados. Ele aparece bem definido em duas histórias de Sagarana: "Minha gente" e "São Marcos". Na primeira, surge como uma espécie de brasão solar, que furta São Jorge à Lua, para simbolizar na imagem o tema que será explorado na história: o da luta do homem com a natureza para não se deixar dominar por ela e superá-la numa instância mais elevada, como foi a luta do santo guerreiro contra o dragão da maldade. Isso acontece quando, na viagem do primo, da estação de trem à fazenda, a comitiva está subindo a cavalo a serra, num fim de tarde. Dessa perspectiva, olhando de baixo para cima, o protagonista e os acompanhantes têm uma visão que, se bem decifrada pelo leitor, lhe revelará o invisível, quer dizer, o tema intelectual que será desenvolvido na narrativa. A cena é apresentada como uma ekphrasis, no modo de a heráldica descrever os brasões medievais; isso é lembrado pelos termos que usa do português antigo, como "cirros", "trabéculas", "blau”, e pela sintaxe paratática, que simplesmente justapõe os elementos alegóricos de que se utiliza nas composições:

E continuamos, seguindo o sol, quase em tramonto - um sol de recorte nítido, não ofuscante. Refrescou. E a estrada subia e descia, mas, como as descidas eram muito menores, nós subíamos sempre. A tarde tinha recuado. Um resto de cirros, no alto, em alvas trabéculas rarefeitas; um empilhado de faixas, tangerina e rosa, no poente; no mais, o céu era lisa campânula de blau.

De brusco, no tope do outeiro que íamos galgando, surgiu um cavaleiro, caído do sol. Ficou parado, um momento, sopesando a vara longa. E era bem um São Jorge, enrolado em claridade amarela e coroado de um resplendor carmesim. (ROSA, 1971: 182) 
E a novela "Minha gente" abre a sua última parte com uma visão lunar do herói. É esse astro que preside o seu estado melancólico, quando, longe, sofre pelo amor não correspondido da prima, com os mugidos soturnos das vacas expressando o seu estado de ânimo: ele, separado do seu amor, como "as vacas apartadas dos bezerros". Porém, no retorno para a fazenda, onde está a prima, será ela, a santa prima Irma, que o ajudará a superar as tendências românticas regressivas e incestuosas e encontrar o seu verdadeiro amor:

Mais sofri, todavia, porque lua havia, uma lua onde cabiam todos os devaneios e em que podia beber qualquer imaginação. Da varanda, eu espiava um pedaço, dado ao luar, de ar claro; as árvores ficavam tão quietas, que aquele campo parecia correr, como um vau de riacho raso, de transparência movente. As vacas, àquela hora, mugiam imenso, apartadas dos bezerros. Os dias me cansavam muito, mas eu não conseguia dormir. Pelas frinchas da janela, entrava o mato em insônia, com vozes que eu não entendia. E, às vezes, tarde na noite, ouvia do curral, bruscos estrépitos - bufos, pisoteios, e um trafegar a esmo excursões do gado sonambúlico.

E eu pensava sempre em Maria Irma. (ROSA, 1971: 218)

$\mathrm{Na}$ segunda história, "São Marcos", esses mesmos motivos, o solar e o lunar, voltarão a aparecer, abrindo e fechando a narrativa. E é nela que, pela primeira vez, aparecerá representada como um conjunto a tríade amorosa do autor. Sobre o assunto já discorri em meu livro O Brasil de Rosá. Por isso, vou me concentrar nas representações simbólicas dessa dança do Sol e da Lua. Logo no início da história, deparamos com um brasão solar:

Bobagens! No céu e na terra a manhã era espaçosa: alto azul, gláceo, emborcado; só na barra sul do horizonte estacionavam cúmulos, esfiapando sorvete de coco; e a leste subia o sol, crescido, oferecido - um massa-mel amarelo, com favos brilhantes no meio a mexer. (ROSA, 1971: 227)

\footnotetext{
${ }^{2}$ Boa parte do estudo foi feita com recortes extraídos de meu livro O Brasil de Rosa - o amor e o poder. São Paulo: Editora UNESP, 2004.
} 
No novo brasão, o Sol aparece num campo azul, atravessado por cúmulos como faixas brancas, e com um valor em si: uma fonte abundante de alimento e luz, "um massa-mel amarelo, com favos brilhantes no meio a mexer". Mas ele só se revelará na sua grandeza, como fonte de luz e calor, quando as forças terrenas forem derrotadas. Isso acontece com a luta do protagonista, representado como o próprio autor, aspirante ao celeste, com o mestre do catimbó, João Mangolô, que aqui reproduz os movimentos da terra:

- E que mais? - Outro safanão, e Mangolô foi à parede e voltou de viagem, com movimentos de rotação e translação ao redor do sol, do qual recebe luz e calor. (ROSA, 1971: 254)

E a história tem como fecho um brasão lunar, com a luz do astro transparecendo no boi branco:

$\mathrm{Na}$ baixada, mato e campo eram concolores. No alto da colina, onde a luz andava à roda, debaixo do angelim verde, de vagens verdes, um boi branco, de cauda branca. E, ao longe, nas prateleiras dos morros cavalgavam-se três qualidades de azul. (ROSA, 1971: 255)

As novelas do livro Corpo de baile encenam o percurso de um dia inteiro, da manhã à noite. Começa como uma madrugada, com o despertar de um menino para a vida, Miguilim, e a desagregação de uma falsa família patriarcal, cujos membros morrem ou se dispersam, para terminar nas noites eróticas de uma nova família que irá se formar, com o mesmo Miguilim, já homem feito, na fazenda Buriti. A estória de Lélio e Lina está próxima do centro do livro; na primeira edição, em dois volumes, e na segunda, num único, é a terceira das sete estórias, o que no ciclo do dia equivaleria ao momento em que o Sol fica mais forte, quase a pino. Ela se passa na fazenda do Pinhém, onomatopéia que reproduz o grito do gavião, a ave solar, Horus, filho de Osíris e Ísis do Egito. É nela que Guimarães experimenta e desenvolve mais claramente a sua concepção da tríade amorosa, que havia representado nas árvores da novela "São Marcos". Agora ela aparece como os três amores, com três mulheres diferentes, que Lélio vive em três estações do ano: primavera, verão e inverno - o outono, quase um quarto amor, o de Mariinha, só 
acontece como um breve amor apagado, uma passagem tênue entre os falsos e o verdadeiro amor, encarnados nas figuras de Sinhá-Linda, a mocinha do Paracatu, de Jiní e de Rosalina. Quando se realiza de fato o encontro de Lélio e Lina, depois de muitas idas e vindas, aproximações e afastamentos, o amor de inverno ou da maturidade, integral e verdadeiro, é apresentado como uma dança do Sol, Lélio/Hélio, com a Lua, Rosalina/Lina/Zália/Rosa, cujo nome variava como as fases da Lua, e é assim que é encenado e descrito:

Desde o mais, o Pernambo pôs o verso para Dona Rosalina, que rezado:... Vi o coração do campo, vi o rastro do luar; vejo dona Rosalina, mas nem posso comparar... Dona Rosalina botara um vestido preto, lustroso, a gola escondia todo o pescoço, presa por debaixo do queixo, e os cabelos dela, tão arranjados, tão branquinhos, alumiavam. Ela parecia uma das pessoas mais influídas e alegradas: fazia rumor nenhum, mas como que animava o engenho da festa. [...] De seguida, se dançou. Quem propôs mesmo foi a dona Rosalina: falou que, sem dança, festa devia a festa. Formaram pares: [...] dona Rosalina veio sorrindo, pegou no braço dele, que era o seu Mocinho - os dois formaram a mazurca dançando. À parte Lélio não se disse a desdém, de dançar com a velhinha antes sopresava-o o afago de todo carinho tanto respeito, uma ausência de si, feito fosse aquela dança uma arte de religião, aprendida por sempre, fora do crédito vem-vai das coisas - mar o mar. No uso do momento, semelhante se esquecido, não temia nem queria nem consistia nada, mas lá. Al a Velhinha se asia tão delicada, senhora de serenim, em giro de baile, leve espécie de criança, que sabia ser e sorrir e olhar, sem estorvo nenhum. - "Meu Mocinho... - ela disse ...antes eu não encontrei você, não podia, meu filho, porque a gente não estava pronta de preparada..." “- E eu, mãe?" - ele perguntou, sem primeiro se esclarecer. - "Uma estrelinha brilha, um átimo, na barra da madrugada, antes d'o sol sair..." - assim ela respondeu. (ROSA, 1976: 205-8, grifo meu)

No Grande sertão: veredas observamos esse mesmo movimento de aproximação e distância, como o dos astros Sol e Lua, entre os dois protagonistas, Riobaldo e Diadorim. Ele vem acrescido, porém, de novas significações. Agora ele ocorre como as reações contraditórias de atração e repulsa vividas pelos amantes. Por um lado, por supor um amor transgressivo, homossexual, o que negaria a natureza guerreira e jagunça de ambos; e, por outro, por haver 
também a possibilidade de ser incestuoso, um amor entre meio-irmãos, filhos do mesmo pai. A isso se acrescenta uma dimensão mítica, a do amor entre Apolo e Ártemis, os dois irmãos que representam o Sol e a Lua na mitologia grega. Ao longo de todo o romance se encena esse movimentoquase-dança de atração e repulsa entre Riobaldo e Diadorim, como os passos de um amor interdito e impossível, cuja realização traria as mesmas ameaças dos eclipses: confundir o dia com a noite e se restabelecer o caos no cosmos. Irei aqui apenas mostrar como em cada momento que se defrontam ou se afastam, sutilmente, o autor faz questão de disseminar nas descrições as sugestões de um encontro cósmico e mítico.

Num momento em que Riobaldo, junto com Sesfredo, acompanha o comerciante de origem alemã, Vupes, e começa o retorno para o bando de jagunços, bate nele a saudade de Diadorim. No seu relato, ela vem associada com o astro na plenitude, sem que possamos saber se é a lua cheia que, ao sair das nuvens, o lembra do amigo, ou se é como a lua cheia saindo das nuvens que ele se lembra de Diadorim, ou, então, se são as duas coisas, "Bela é a lua, lualã, que torna a se sair das nuvens, mais redonda recortada":

Demos no Rio, passamos. E, aí, a saudade de Diadorim voltou em mim, depois de tanto tempo, me custando seiscentos já andava, acoroçoado, de afogo de chegar, e perto estar. Cavalo que ama o dono, até respira do mesmo jeito. Bela é a lua, lualã, que torna a se sair das nuvens, mais redonda recortada. Viemos pelo Urucuia. Rio meu de amor é o Urucuia. (ROSA, 1963: 70-1)

No dia em que Diadorim revela a Riobaldo o seu segredo, dá-lhe o seu nome e pede-lhe que o chame só assim, Diadorim, eles pegam-se nas mãos e olham-se nos olhos, ficando face a face. Amorosamente, envolvem-se numa atmosfera de encanto e proteção, que se parece com o entardecer ou coincide com essa mesma hora, "sol-se-pôr", quando o Sol está ainda cálido, mas amansado, e a Lua nasce em seu esplendor, e ambos se entrelaçam e marcham como os dois grandes astros na dança do sertão:

Assim eu ouvi, era tão singular. Muito fiquei repetindo em minha mente as palavras, modo de me acostumar com aquilo. E ele me deu a mão. Daquela mão, eu recebia certezas. Dos olhos. Os olhos que ele punha em mim, tão externos, quase 
tristes de grandeza. Deu alma em cara. Adivinhei o que nós dois queríamos logo eu disse: - “Diadorim... Diadorim?' - com uma força de afeição. Ele sério sorriu. E eu gostava dele, gostava, gostava. Aí tive o fervor de que ele carecesse de minha proteção, toda a vida: eu terçando, garantindo, punindo por ele. Ao mais os olhos me perturbavam; mas sendo que não me enfraqueciam. Diadorim. Sol-se-pôr, saímos e tocamos dali, para o Canabrava e o Barra. Aquele dia fora meu, me pertencia. Íamos por um plaino de varjas; lua lá vinha. Alimpo de lua. Vizinhança do sertão - esse Alto-Norte brabo começava. - Esses rios têm de correr bem! - eu de mim dei. Sertão é isto, o senhor sabe: tudo incerto, tudo certo. Dia da lua. O luar que põe a noite inchada. (ROSA, 1963: 149; grifo meu)

Depois de uma batalha, quando estão lutando contra o bando de Zé Bebelo, eles se dispersam. Diadorim, ferido, possivelmente numa das pernas, faz como os bichos, que para não serem surpreendidos enfraquecidos, escondem-se para se curar, embora ele aja assim também para não descobrirem o seu segredo. Riobaldo não sabe para onde ele foi nem como está. Esse distanciamento e a falta, a ausência de Diadorim, são descritos como a lua nova, aqui representada pelo cavalo "murzelo-andrino". Com o negro sobre o negro, duas cores negras superpostas, uma acentuando o escuro da outra, como se fosse a noite, já por si negra, escurecida ainda mais pelo negro da lua nova, cria-se a redundância do preto-negro azulado, sugerindo a bela imagem do cavalo da noite escura montado pela lua nova. Na descrição que o Paspe faz de Diadorim, tudo é indefinido, não se pode afirmar nada sobre o ferimento, o estado ou o paradeiro do amigo; as únicas coisas que são descritas, com detalhe e precisão, são os arreios e o cavalo alto que Diadorim montava, firme e negro-negro, como a lua nova:

Ao que nem não nem sim - mais pelo não que pelo sim... - O Paspe completou. Não tinha reparado, no relance do tempo. Só viu que o arreio era um socadinho, quase novo, e o cavalo alto, desbarrigado, mas pronto de si, riscando com todas as ferraduras, murzelo-andrino... (ROSA, 1963: 216)

Depois do pacto, quando Riobaldo está se afastando de Diadorim para cumprir a sua missão de chefia e guerra, o desencontro dos dois é comparado ao do sol do meio-dia com a lua da meia-noite. Nesse episódio, Diadorim tenta se 
aproximar do herói e promete-lhe, com palavras vestidas de afetos, "com o amor no fato das palavras", contar-lhe "um segredo", depois de cumprida a vingança. Mas Riobaldo estava longe, "de mim e dele", e desentendeu metade do que disse o amigo. Essa distância máxima entre os dois é representada como a existente entre o sol do meio-dia e a lua alta da meia-noite, e a aproximação amorosa de Diadorim, cheia de promessas e palavras doces, é vista por ele como a cena do jegue regredindo à selvageria, caçando no campo o que roer:

Só sei que, no meio reino do sol, era feito parássemos numa noite demais clareada. Assim figuro. Dentro de muito sol, eu estava reparando uma cena: que era um jumentinho, um jegue já selvagem caatingano, no limpo do campo caçando o que roer, assaz pelos cardos. (ROSA, 1963: 480)

Para concluir. Na segunda tentativa de travessia do Sussuarão, agora sob a chefia de Riobaldo/Urutu-Branco, como uma prova para o seu poder de comando, ele se testa e se supera também na coragem: mata um jagunço que o desafiava, só que não a tiro, em que sua destreza era conhecida, mas à faca, a arma por excelência de Diadorim. Se o amigo Reinaldo era o que era e ele, Riobaldo, o que queria ser, com esse ato que o superava, o herói se transformava no outro ou, pelo menos, adquiria o seu estado, ficava à altura do amigo e ocupava o seu lugar. Ele diz que Diadorim o olhava, como se ele "estivesse para trás da lua”. Porém, ele conseguiu isso à custa do sangue, ainda que fosse o de um jagunço que lhe pareceu ser o próprio demo, um danado, que "morreu maldito, morreu com a goela roncando na garganta". Ele sentiu o horror da mancha que o "breava". Foi assim que se viu, enegrecido pelo breu do sangue, coisa que deveria ficar sempre "em entranhas escondida". Esse ato o transformava no seu oposto, Diadorim, como se "estivesse para trás da lua", e a hóstia "alvíssima", como a Lua, era guardada oculta no sacrário de ouro, que tem sempre em sua porta, estampado como a representação de Deus, o Sol resplendente com os raios luminosos. Essas passagens ontológicas de Riobaldo e Diadorim, transitando um para o lugar do outro, ele para trás da Lua e esta para trás do Sol, a hóstia na custódia, cada um assumindo a feição de seu contrário, têm também algo de milagroso, pois não encontram propriamente uma explicação natural nem se dão através de um processo formativo; elas são procuradas apelando-se para as forças obscuras, daí tal- 
vez requererem que se pense numa ritualização do mito e encenarem um sacrifício do bode. São representações que encerram também uma forte suspeita sobre o trânsito dos indivíduos de uma classe para outra (como ocorrera entre eles depois do pacto, quando trocaram as posições de mando e obediência dadas pelo nascimento). Elas implicam também descaracterizações e eliminação de diferenças importantes para manter a ordem e a hierarquia. Depois desses fatos, Riobaldo sai com capacidade de mando e coragem, ainda que em roupagens paródicas, como as do seu bando de estropiados, como os catrumanos, e com ele ladeado pelo menino Guirigó e o cego Borromeu. Aqui, tais trânsitos de uma posição para outra estão representados como um movimento perigoso de confusão do Sol com a Lua, que não podem jamais trocar de lugar, sob pena de estabelecerem o caos e a indistinção, como ameaçam os eclipses. Eles são dois astros que se atraem, mas que estão impedidos de se confundir e se misturar:

Não turveei. Morte daquele cabra era em ramo de suicídios. - "A modo que morreu? Ele foi para os infernos?" - indagou em verdade o menino Guirigó. Antes o que era que eu tinha com isso, como todos me louvaram? Sendo minha a culpa - a morte, isto sei; mas o senhor me diga, meussenhor: a horinha em que foi, a horinha? Como que o cego Borromeu garrou um fanhoso recitar, pelos terços e responsos. Medo de cego não é o medo real. Diadorim me olhava - eu estivesse para trás da lua. Só aí, revi o sangue. Aquele, em minha roupa, a plasta vermelha fétida. Do sangue alheio que grosso me breava, mal me alimpei o queixo; eu, desgostoso de sangue, mas deixava, de sinal? Ah, não, pois ali me salteou o horror maior. Sangue... sangue é a coisa para restar sempre em entranhas escondida, a espécie para nunca se ver. Será por isso também que imensa mais é a oculta glória de grandeza da hóstia de Deus no ouro do sacrário - toda alvíssima! - e que mais venero, com meus joelhos no duro chão. (ROSA, 1963: 483-4)

\section{Referências Bibliográficas}

ROSA, J. G. Grande sertão: veredas. 3. ed. Rio de Janeiro: José Olympio, 1963.

ROSA, J. G. Sagarana. 14. ed. Rio de Janeiro: José Olympio, 1971.

ROSA, J. G. No Urubuquaquá, no Pinbém. 5. ed. Rio de Janeiro: José Olympio, 1976. 
